\title{
The Relationship between Student Teachers' Professional Identity and Anxiety: The Moderating Role of Campus Pressure
}

\author{
Shanyu Lin, Xinqiang Wang*, Liwen Chen, Juncheng Zhu, Yibing Wang \\ Center of Mental Health Education and Research, School of Psychology, Jiangxi Normal University, Nanchang, China \\ Email: *xinqiangw101@163.com
}

How to cite this paper: Lin, S.Y., Wang, X.Q., Chen, L.W., Zhu, J.C. and Wang, Y.B. (2017) The Relationship between Student Teachers' Professional Identity and Anxiety: The Moderating Role of Campus Pressure. Open Journal of Social Sciences, 5, 214-223. https://doi.org/10.4236/jss.2017.56019

Received: May 8, 2017

Accepted: June 19, 2017

Published: June 22, 2017

Copyright $\odot 2017$ by authors and Scientific Research Publishing Inc. This work is licensed under the Creative Commons Attribution International License (CC BY 4.0).

http://creativecommons.org/licenses/by/4.0/

\begin{abstract}
Objective: To understand the relationship between professional identity of student teachers and anxiety, and to explore the moderating effect of campus pressure after controlling demographic variables. Methods: A questionnaire survey was conducted among 325 student teachers by using the Professional identity scale, State-Trait Anxiety Inventory and Campus stress scale. Results: 1) Professional identity of student teachers is an influencing factor of anxiety, and it can be significantly negative to predict the degree of anxiety. 2) Campus pressure plays a moderating role in the relationship between professional identity and anxiety; it negatively impacts the relationship between professional identity and anxiety. Conclusion: The relationship between student teachers' professional identity and anxiety is moderated by the pressure of the campus.
\end{abstract}

\section{Keywords}

Student Teachers, Professional Identity, Anxiety, Campus Pressure

\section{Introduction}

For the training and development of student teachers, the previous scholars are more focused on emphasizing the development of student teachers' professional knowledge and professional competence [1]. However, with the deepening of research, scholars have become increasingly clear that the real promotion of student teachers' career development is their professional identity, whether they are willing to be an educator [2]. Professional identity can be defined as the extent to which a person agrees with his profession and to what extent he feels that he is part of a professional field, is the individual on a field of occupation commitment and positive attitude, reflected in the individual's love of the occupation 
and the desire to continue to engage in the profession [3]. Professional identity is a combination of beliefs, values, motivations, and experiences, and people define their own values through this professional role [4]. It is the concept of a number of researches in the field of psychological education research, especially in the study of professional identification of student teachers.

Student teachers' professional identity, in the research of other scholars also known as the pre-service teachers' professional identity, is an important research direction in psychological education; the researchers believe that it is the psychological basis and key for the student teachers to become teachers in many studies; there is not a very uniform conceptual definition of student teachers' professional identity [5]. Some people think that student teachers' professional identity is a dynamic process [6]. From this point of view, the professional identities of student teachers and vocational teachers are both similar and different. On the basis of literature analysis and interview study, Wang Xinqiang et al. (2010) defined the professional identity of the student teachers as full acceptance and recognition of the upcoming teacher career and the current student teacher identity. Four dimensions were contained: professional willing (indicating their expectations and prepare for the teacher career, three items, e.g., "I am willing to communicate with pupil."), professional volition (indicating they are still willing to long engaged in the teacher career in the face of other career options, three items, e.g., "I'll do teacher with lifetime."), professional values (mainly focused on value judgment about the teaching profession, three items, e.g., "I think student teachers is respected."), and professional efficiency (mainly focused on self-efficacy about the teaching profession, three items, e.g., "I have an ability to master the teaching skill.”) [2]. According to Xinqiang Wang's professional identity structure, which reflects the professional efficiency of is the identity of individual own ability and their ability to match with the teacher's professional evaluation, professional value is mainly reflected in the professional identity of individual's own identity of student teachers and the professional value of teachers' emotional experience [5] [7]. The professional willing, professional volition is the individual's behavior derived from the commitment and goal expectations on the basis of the professional performance and professional value, is the result of professional identity. Among them, professional willing is the expectation and preparation of the student teachers in the teaching profession; professional volition is the behavioral commitment of student teachers to overcome temptation or difficulty [7].

At present, the research on the student teachers at China and abroad mainly focuses on the research on the current situation of the professional identity of student teachers, the theoretical discussion and the compilation of tools. The study on the professional identity of student teachers is not enough, and the research on the influence of the student teachers' professional identity on their mental health and their learning life is rare. However, there is little research on the relationship between student teachers' professional identity and anxiety.

Anxiousness is a kind of anxiety, tension, anxiety, and fear of negative emo- 
tions when individual has on the present or future foreseeable frustration, which is usually a diffuse and vague feeling that it may focus on a particular idea, such as fear of disease death; may also appear in specific circumstances, such as concerns about future career. College students are prone to psychological problems hurt people likely to suffer from depression and anxiety; anxiety will affect the students in professional and personal aspects, including personal consequences of substance abuse, deteriorating health and physical activity decreased, professional consequences including academic performance degradation, moral decline and academic fraud etc [8]. For the student teachers, their mental health is a focus of educational administrators and society, because it is related to the development of education and social stability in the future.

Facing the current increasingly serious employment situation, the anxiety level of the student teachers is easy to rise because of lack of professional identity. There are even some students who are too anxious about their future career development. In the real world, the anxiety of college students due to weak professional identity has become increasingly prominent. According to the scholar's social model based on mental health study can be found, personal career choices will have an impact on people's mental health, therefore, the weak professional identity of the student teachers will also determine whether they will have a negative impact on mental health because they were about to become an educator, such as anxiety. Therefore, research and analysis of the relationship between professional identity and anxiety and to explore the effect of campus pressure on its moderating role, which will help to understand the influence of the professional identity status of student teachers on their anxiety, and will put forward concrete countermeasures for the effective training and intervention of student teachers.

The pressure among campus students can be simply defined as the psychological and physiological state of the students who face the threat of stress in the campus, usually in the student's daily life, will make the student's personal style of life and behavior change [9]. On the basis of literature reading and data inquiry, this study suggests that campus stress may play a moderating role in the relationship between professional identity and anxiety, the fewer the pressure on the campus the closer the relationship between the two. In other words, under low pressure on the campus, the higher the professional identity, the lower the anxiety of the student teachers.

Based on the relevant theory, this study considers campus pressure as an important factor and explores its moderating role in the relationship between professional identity and anxiety. The data obtained from the questionnaire is analyzed and tested to explore the student teachers' professional identity, anxiety and the relationship between these three pressures, in order to student teachers for the effective development of mental health education to provide a new theoretical basis. On the basis of this, two hypotheses are put forward. Hypotheses 1: student teachers' professional identity can significantly predict the degree of anxiety of student teachers. Hypotheses 2: The campus pressure plays a moderat- 
ing role in the relationship between professional identity and anxiety. Proposed model of hypothesis shown in Figure 1.

\section{Research Methods}

\subsection{Subject}

The subjects of the study were collected from major universities in Jiangxi Province, and randomly selected students were surveyed at different grades of colleges and universities. A total of 400 questionnaires were distributed and 325 valid questionnaires were collected, including 77 boys and 248 girls; freshman sophomore students a total of 158 students, juniors and seniors a total of 167; students of the average age of 20 years old.

\subsection{Materials}

\subsubsection{Professional Identification Scale for Student Teachers}

Using the scale compiled by Wang Xinqiang et al. (2010), which has good reliability and validity, including 12 items, using a 5-point score, there are four dimensions: professional volition, professional willing, professional efficiency and professional values [2]. The scale according to the score to determine the level of professional identity of student teachers, it can be used for related research [10]. The Cronbach's $\alpha$ for the scale was 0.835 in the current study.

\subsubsection{Anxiety Scale}

The study was conducted using S-AI from the STAI (state-trait anxiety inventory), compiled by Charles D Spielberger et al. [11]. The scale can be widely used in the evaluation of personal anxiety, can also be used for screening for college students, soldiers and other people related to anxiety. The Cronbach's $\alpha$ for the scale was 0.917 in the current study.

\subsubsection{Campus Pressure Scale}

This study used Li Hong et al. (2002) to prepare the student teachers stress scale [12]. The scale reliability is good, from the study annoyance, personal annoyance and negative life events three subscales composed of 30 topics, using 4 points score, the theoretical score range of 0 - 90 points, the higher the score that the greater the pressure. The Cronbach's $\alpha$ for the scale was 0.912 in the current study.

\subsection{Procedures}

Using random sampling method, subjects were asked to fill the questionnaire,

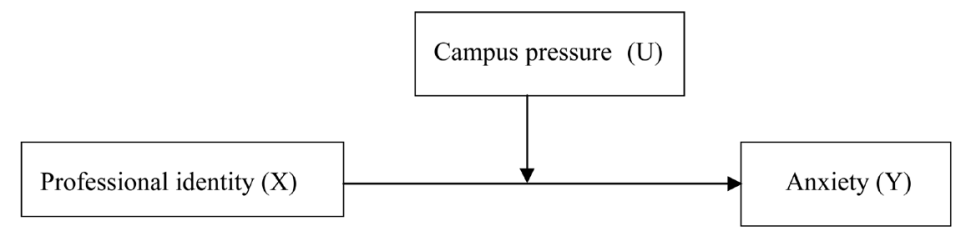

Figure 1. Proposed model of hypothesis. 
questionnaire bearer, complete the questionnaire takes about 20 - 25 minutes, all the questionnaires on the spot recycling, and then unified data analysis.

\subsection{Data Processing}

Using Epi-data software to enter data, the data were analyzed by SPSS21.0 software. Data analysis mainly included descriptive statistics, correlation analysis and regression analysis.

\section{Result}

\subsection{An Analysis of the Current Situation and Characteristics of Student Teachers' Anxiety}

According to the description of the questionnaire, the results show that the average score of the student teachers' state anxiety is 22.10 , and the average scores of major, gender and grade were also lower than 40 points, and the degree of anxiety of students from normal university was in the middle level of anxiety. Although the general situation of student teachers are moderate anxiety state, but from the percentage of individual anxiety to the percentage of individual view, some of which anxiety ( 20 points below) accounted for $43.8 \%$, moderate anxiety ( 20 points to 40 points) accounted for $51.2 \%$, very obvious anxiety ( 40 points or more) accounted for 5\%. It can be seen that most of the student teachers have a certain degree of anxiety, but the degree of anxiety varies from person to person, there are few individual students have anxiety disorder.

\subsection{Correlation Analysis of Professional Identity, Anxiety and Campus Stress in Student Teachers}

There was a significant negative correlation between professional identity and state anxiety $(\mathrm{r}=-0.275, p<0.01)$. There was a significant positive correlation between campus pressure and state anxiety $(\mathrm{r}=0.523, p<0.01)$. Professional identity was significantly negatively correlated with campus stress $(\mathrm{r}=-0.183, p$ $<0.01$ ) and was suitable for use as the empirical test of campus stress's moderating effect.

\subsection{The Moderating Effect of Campus Pressure on the Relationship between Professional Identity and Anxiety in Student Teachers}

In addition to gender, grade, all variables for the central processing. As shown in Table 1, the first step of the equation is placed in the demographic variable sex and grade, $\Delta R^{2}$ is 0.014 . The second step into the professional identity (X) and the campus pressure $(\mathrm{U})$, the two main effects are significant, respectively, $\beta_{\text {professional identity }}=-0.198, \mathrm{t}=-4.109, p<0.001 ; \beta_{\text {campus pressure }}=0.511, \mathrm{t}=10.888, p<$ $0.001, \Delta R^{2}$ is 0.328 . This confirms that professional identity $(\mathrm{X})$ has a predictive effect on anxiety $(\mathrm{Y})$. The third step into the professional identity $\times$ campus pressure (UX), the moderating effect is significant, $\beta_{\text {campus stress } \times \text { professional identity }}=$ $0.192, \mathrm{t}=4.152, p<0.001, \Delta R^{2}$ is 0.034 , that is, the campus stress play a moderating role in the relationship between professional identity and anxiety. 
Table 1. Regression analysis of anxiety as dependent variable.

\begin{tabular}{cccccccc}
\hline \multirow{2}{*}{ Independent variable } & \multicolumn{2}{c}{ The first step } & \multicolumn{2}{c}{ The second step } & \multicolumn{2}{c}{ The third step } \\
\cline { 2 - 8 } & \multicolumn{2}{c}{$\beta$} & $t$ & $\beta$ & $t$ & $\beta$ & $t$ \\
\hline Gender* & -0.085 & 1.509 & -0.176 & $-3.746^{* * *}$ & -0.184 & $4.007^{* * *}$ \\
Grade & 0.072 & 1.291 & 0.070 & 1.498 & 0.069 & 1.496 \\
Professional identity(X) & & & -0.198 & $-4.109^{* * *}$ & -0.204 & $4.356^{* * *}$ \\
Campus pressure(U) & & & 0.511 & $10.888^{* * *}$ & 0.460 & $9.708^{* * *}$ \\
UX & & & & & 0.192 & $4.152^{* * *}$ \\
$R^{2}$ & 0.014 & & 0.342 & & 0.376 \\
$\Delta R^{2}$ & 0.014 & & $0.328^{* * *}$ & & $0.034^{* * *}$ \\
$F$ & 2.190 & $40.891^{* * *}$ & \multicolumn{2}{c}{$37.848^{* * *}$} \\
\hline
\end{tabular}

Note: ${ }^{*} p<0.05,{ }^{* *} p<0.01,{ }^{* *} p<0.001, a: 1=$ male, $0=$ female.

To explain the moderating effect, according to the regression equation, respectively, take the campus pressure (U) positive and negative standard deviation to draw a simple effect analysis [13], as shown in Figure 2. The simple slope test shows that anxiety $(\mathrm{Y})$ shows a significant downward trend with the increase of professional identity $(\mathrm{X})$ when the campus pressure $(\mathrm{U}=1)$ is high $(\beta=$ $-1.848, \mathrm{t}=-25.8899, p<0.001)$, comprehending professional identity $(\mathrm{X})$ to increase a standard deviation, anxiety will reduce the 1.848 standard deviation. In the weak pressure on the campus $(\mathrm{U}=-1)$, anxiety $(\mathrm{Y})$ showed a significant downward trend $(\beta=-2.232, \mathrm{t}=-30.3092, p<0.001)$ with the increase in professional identity $(\mathrm{X})$, comprehension of professional identity $(\mathrm{X})$ for each additional standard deviation, anxiety $(\mathrm{Y})$ will reduce the standard deviation of 2.232 , relative to the campus pressure $(\mathrm{U})$ is high, the magnitude of anxiety reduction is greater. In other words, for student teachers with lower campus pressure (U), the impact their professional identity has on anxiety has been strengthened. Student teachers' professional identity can negatively predict the degree of anxiety of student teachers, and the pressure of campus plays a moderating role in the relationship between professional identity and anxiety in student teachers, and has a reduced effect on the influence between professional identity and anxiety. Hypothesis 1 and Hypothesis 2 are supported.

\section{Discussed}

\subsection{The Relationship between Professional Identity and Anxiety of Student Teachers}

Professional identity is an important factor in the anxiety of student teachers. This study uses an improved scale to exclude the confusion of the relationship between impulsivity and professional identity. The analysis of career identity is more accurate and the conclusion of the relationship between professional identity and anxiety is more reliable. The different professional identity has a direct impact on the student teachers' anxiety. As a combination of beliefs, values, motivation and experience, professional identity represents a person's professional 


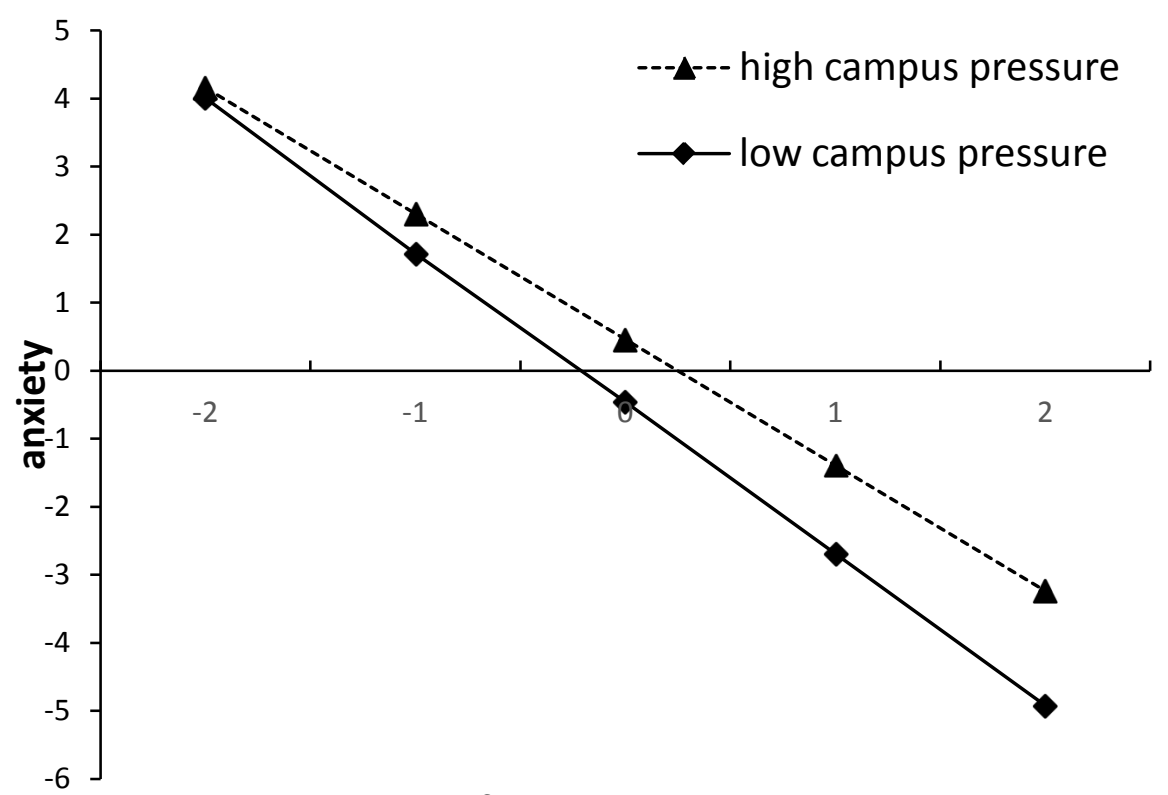

\section{professional identity}

Figure 2. The moderating effect of campus pressure on the professional identity and anxiety of student teachers.

identity, which can effectively affect the psychological state of student teachers. Anxiety refers to an individual's emotional state of worry, tension and fear. From the definition of the two, we can directly see the importance of professional identity to the anxiety of student teachers. There is a significant negative correlation between professional identity and state anxiety. The results show that the professional identity will affect the formation of the normal college students' anxiety, and the students with higher professional identity will show a lower level of anxiety. It is also confirmed that the students with high professional identity are not prone to negative emotions such as anxiety. The results of this study are consistent with these findings.

There is a close relationship between professional identity and anxiety in student teachers, professional identity is an important factor in mental health, especially anxiety. The professional identity of the student teachers will also determine whether they will have a negative impact on mental health because they were about to become an educator, such as anxiety. Good professional identity allows teachers to form a positive attitude towards life, and the future is full of hope, not susceptible to anxiety, depression and other negative emotions, and weak professional identity is easy to lead to anxiety and depression and other negative emotions. This is in part to the psychological health of the sociological model theory, that is, the individual's mental health will be affected by their professional identity and other factors [14]. At the same time, it also increases the generalization of the relationship between professional identity and anxiety, highlights the importance of professional identity in the education and cultivation of student teachers, and the important influence of professional identity on student teachers' mental health. 


\subsection{The Moderating Role of Campus Pressure}

In this study, the model of the influence of professional identity on anxiety adds the problem of the stronger or weaker qualitative condition-the moderator variable, which is further deepened and expanded. The results show that campus pressure will have an impact on the relationship between professional identity and anxiety in student teachers, which is consistent with previous studies [15] [16]. When the campus pressure is weak, with the increase of the professional identity of student teachers, anxiety shows an extremely significant downward trend, and compared with the higher campus pressure, the anxiety reduction is more significant. That is to say, the influence of the normal school students' professional identity on the anxiety will be more closely when the campus pressure is smaller.

When the campus pressure this situation exists, if student teachers have a lower sense of professional identity and haven't take appropriate countermeasures, it will lead to anxiety and other negative emotions, adverse health; according to the different campus pressure situation to take appropriate strategies to improve professional identity will help to reduce the anxiety of student teachers, reduce the negative emotions caused and it plays an important role in the mental health of student teachers.

Although the professional identity can significantly predict the level of anxiety of student teachers, but the level of professional recognition of the normal level of anxiety is not exactly the same. In this study, the interaction between individual and the environment is discussed, and the condition of professional identity to anxiety is given to the student teachers. It is checked whether the campus pressure has a moderating effect on the relationship between professional identity and anxiety. The results show that the campus pressure is actually one of the factors that affect students' anxiety. More importantly, the campus pressure on the student teachers of professional identity and the relationship between anxieties has a moderating role. That is to say, the campus pressure plays a role similar to "catalyst" in the influence of the students' professional identity on the anxiety.

From another point of view, regardless of the level of stress on campus, the weak professional identity of student teachers' anxiety level will be relatively higher. The simple moderating effect test shows that when the campus pressure is high, the professional identity and anxiety will be significantly negative correlation; when the campus pressure is weak, professional identity and anxiety will be significant and strong negative correlation. Therefore, reduce the pressure of the campus is beneficial for the student teachers with higher professional identity. This model has two implications for us: First, in the lower campus pressure, improve professional identity can significantly reduce the anxiety of student teachers, but also can improve the student teachers of learning input; Second, do not overly exaggerate professional identity of this variable on the role of anxiety, in the high campus pressure, the role of professional identity to reduce the anxiety of student teachers is actually relatively limited. Therefore, this suggests 
that we should understand, prevent and interfere with the mental health of student characteristics and environmental interaction. In order to reduce their anxiety, student teachers not only need to raise professional identity, but also should release their stress. Last but not least, catalytic effect brought by campus pressure need to be weakened.

\section{Conclusions and Its Practical Implications}

1) Professional identity of student teachers is an influential factor of anxiety and professional identity can be significantly negative to predict the degree of anxiety of student teachers. In this regard, the psychological contract is proposed as follows: the state raises the social status of teachers by increasing investment in education. The salaries of primary and secondary school teachers should be improved, especially in rural or remote areas. Improve the professional status of teachers. Student teachers should continue to improve their professional ability during their school years, make them indispensable and cannot be replaced. At this point, student teachers' professional identity will be improved.

2) Campus pressure in the relationship between professional identity and anxiety plays a moderating role; the impact of professional identity and anxiety has reduced effect. Therefore, psychological health education is essential for student teachers to pay attention to the emotional state of student teachers, and try to create a relaxed psychological atmosphere for them. During the period of school assessment, team work is adopted to reduce individual competition, enhance the gregarious behavior of student teachers. It not only helps teachers to get a sense of belonging and identity, but also helps to vent their negative emotions. Teachers have a sense of happiness; they will release more love to students to train more students with love.

\section{Acknowledgements}

This work was supported by the Jiangxi Normal University Project of Humanities and Social Sciences "The Cultivation Mechanism Innovation and Quality Monitoring Research of Free Normal Students Based on the Professional Identity Perspective"; the Science Foundation for Young Scholars of Jiangxi Province (20151BAB215033); the Graduate Student Innovation Project of Jiangxi Province (YC2016-S136).

\section{References}

[1] Cochran-Smith, M. (2000) The Questions that Drive Reform. Journal of Teacher Education, 51, 331-333. https://doi.org/10.1177/0022487100051005001

[2] Wang, X.Q., Zeng, L.H., Zhang, D.J. and Li, S. (2010) The Initial Preparation of Professional Identification Scale for Student Teachers. Journal of Southwestern University: Social Science Edition, 36, 152-157.

[3] Vivekananda-Schmidt, P., Crossley, J. and Murdoch-Eaton, D. (2015) A Model of Professional Self-Identity Formation in Student Doctors and Dentists: A Mixed Method Study. BMC Medical Education, 15, 1-9. https://doi.org/10.1186/s12909-015-0365-7 
[4] Yu, K.H., Kim, S. and Restubog, S. (2015) Transnational Contexts for Professional Identity Development in Accounting. Organization Studies, 36, 1577-1597. https://doi.org/10.1177/0170840615593586

[5] Wang, X.Q. and Xiao, M.Y. (2014). Status Survey and Countermeasures on Normal senior students' Teachers Professional Identity from Education Quality Evaluation and Monitoring Perspective. Contemporary Teacher Education, 7, 48-53. https://doi.org/10.16222/j.cnki.cte.2014.03.015

[6] Conway, P.F. (2001) Anticipatory Reflection While Learning to Teach: From a Temporally Truncated to a Temporally Distributed Model of Reflection in Teacher Education. Teaching \& Teacher Education, 17, 89-106.

[7] Wang, X.Q., Zhang, D.J. and Zeng, L.H. (2011) Professional Value and Professional Efficacy: The Dual Core Factor Model of Professional Identity in Normal Students. Psychological Development and Education, 27, 662-669. http://doi.org/10.16187/j.cnki.issn1001-4918.2011.06.005

[8] Tabalipa, F.D.O., Souza, M.F.D., Pfützenreuter, G., Lima, V.C., Traebert, E., Traebert, J., et al. (2015) Prevalence of Anxiety and Depression among Medical Students. Revista Brasileira De Educação Médica, 39, 388-394. https://doi.org/10.1590/1981-52712015v39n3e02662014

[9] Lucier, K.L. (2014) College Stress Solutions: Stress Management Techniques for Beating Anxiety, Making the Grade, and Enjoying the Full College Experience. Adams Media.

[10] Wang, X.Q., Zhu, J.C., Liu, L. and Chen, X.Y. (2017) Cognitive-Processing Bias in Chinese Student Teachers with Strong and Weak Professional Identity. Frontiers in Psychology, 8, 1-9. https://doi.org/10.3389/fpsyg.2017.00784

[11] Spielberger, C.D. (2010) State-Trait Anxiety Inventory. Corsini Encyclopedia of Psychology. John Wiley \& Sons, Inc., Hoboken. https://doi.org/10.1002/9780470479216.corpsy0943

[12] Li, H. and Kam, W.B. (2002) Types and Characteristics of College Stress. Psychological Science, 25, 398-401.

[13] Dearing, E. and Hamilton, L.C. (2006) V. Contemporary Advances and Classic Advice for Analyzing Mediating and Moderating Variables. Monographs of the Society for Research in Child Development, 71, 88-104. https://doi.org/10.1111/j.1540-5834.2006.00406.x

[14] Wang, X.Q. and Zhang, D.J. (2012) The Relationship between Professional Identity and Mental Health of Tuition-Free Normal University Students and Its Enlightenment. Contemporary Teacher Education, 5, 62-67. http://doi.org/10.16222/j.cnki.cte.2012.04.017

[15] Extremera, N., Durán, A. and Rey, L. (2009) The Moderating Effect of Trait Meta-Mood and Perceived Stress on Life Satisfaction. Personality \& Individual Differences, 47, 116-121.

[16] Weinstein, L. and Laverghetta, A. (2009) College Student Stress and Satisfaction with Life. College Student Journal, 43, 1161-1162. 
Submit or recommend next manuscript to SCIRP and we will provide best service for you:

Accepting pre-submission inquiries through Email, Facebook, LinkedIn, Twitter, etc. A wide selection of journals (inclusive of 9 subjects, more than 200 journals)

Providing 24-hour high-quality service

User-friendly online submission system

Fair and swift peer-review system

Efficient typesetting and proofreading procedure

Display of the result of downloads and visits, as well as the number of cited articles Maximum dissemination of your research work

Submit your manuscript at: http://papersubmission.scirp.org/

Or contact jss@scirp.org 